\title{
PROBLEMS IN THE EARLY DIAGNOSIS AND MANAGEMENT OF CONGENITAL DISLOCATION OF THE HIP
}

\author{
George P. Mitchell, Edinburgh, Scotland \\ From the Princess Margaret Rose Orthopaedic Hospital and the \\ Simpson Maternity Pavilion, Royal Infirmary, Edinburgh
}

The treatment of congenital dislocation of the hip from birth should give excellent results in almost every case under adequate supervision. Nevertheless difficulties still arise despite increasing awareness and more regular routine examination of the newborn. Accurate examination and treatment can be organised with less difficulty in large maternity units than in small units, peripheral hospitals or homes.

The problems in early management are, first, the missed dislocation; and second, the complications of treatment.

\section{THE MISSED DISLOCATION}

The disorder can escape detection at birth even with adequate staffing arrangements. In the large Simpson Maternity Unit in Edinburgh four dislocations were missed out of 31,961 births in the seven years 1962 to 1968 inclusive and were diagnosed later after walking began (Table I). This amounted to one missed dislocation per 8,000 births.

All infants were examined soon after birth by the paediatrician, and those with a positive "clunk" test on one or both sides were re-examined by the orthopaedic surgeon within a few days. When the test was confirmed the condition was classified as a luxation and the hips were held in flexion and abduction by a Malmö splint (von Rosen 1962). When the "clunk" was not confirmed but when laxity was found the hips were classified as unstable. When no abnormality could be discovered the hips were classified as normal.

TABLE I

Details of Hips Notified at the Simpson Maternity UNIT from 1962 to 1968 InClusive

\begin{tabular}{|c|c|c|c|c|c|c|c|c|}
\hline Year & $\begin{array}{l}\text { Number } \\
\text { of births }\end{array}$ & $\begin{array}{l}\text { Luxation } \\
\text { of hips }\end{array}$ & $\begin{array}{l}\text { Unstable } \\
\text { hips }\end{array}$ & $\begin{array}{l}\text { Suspected } \\
\text { but normal }\end{array}$ & $\begin{array}{c}\text { Dislocation } \\
\text { missed }\end{array}$ & $\begin{array}{l}\text { Deformity } \\
\text { epiphysis } \\
\text { metaphysis }\end{array}$ & Hip $_{\text {operation }}$ & $\begin{array}{l}\text { Derotation } \\
\text { osteotomy }\end{array}$ \\
\hline 1962 & 3,980 & 15 & 16 & 8 & 1 & 1 & 1 & \\
\hline 1963 & 4,023 & 12 & 8 & 13 & & & & \\
\hline 1964 & 4,617 & 7 & 7 & 9 & 1 & & & \\
\hline 1965 & 4,711 & 20 & 28 & 42 & & 1 & 3 & 1 (1969) \\
\hline 1966 & 5,003 & 12 & 23 & 30 & 1 & & & \\
\hline 1967 & 4,956 & 11 & 16 & 9 & 1 & & & \\
\hline 1968 & 4,671 & 23 & 28 & 12 & & & 1 & \\
\hline Total & 31,961 & 100 & 126 & 123 & 4 & 2 & 5 & 1 \\
\hline \multicolumn{2}{|c|}{$\begin{array}{l}\text { Incidence of luxation } \\
\text { per } 1,000 \text { births }\end{array}$} & 3 & & & & & & \\
\hline
\end{tabular}

Approximately 50 per cent of the births were in primiparae. 
In the unstable group there were some hips in which the "clunk" sign was not confirmed but in which the radiographs showed displacement; in these cases the Malmö splint was applied. It is realised that interpretation of radiographs at birth is difficult, but they are of some value in the group where the "clunk" sign rapidly disappears due to early tightening of the capsule.

Particular care should be taken when there is a strong family history of dislocation, and in such cases routine radiographs are considered justifiable. The radiograph in Figure 1 suggest partial displacement of the right hip at four weeks in an infant whose "clunk" test

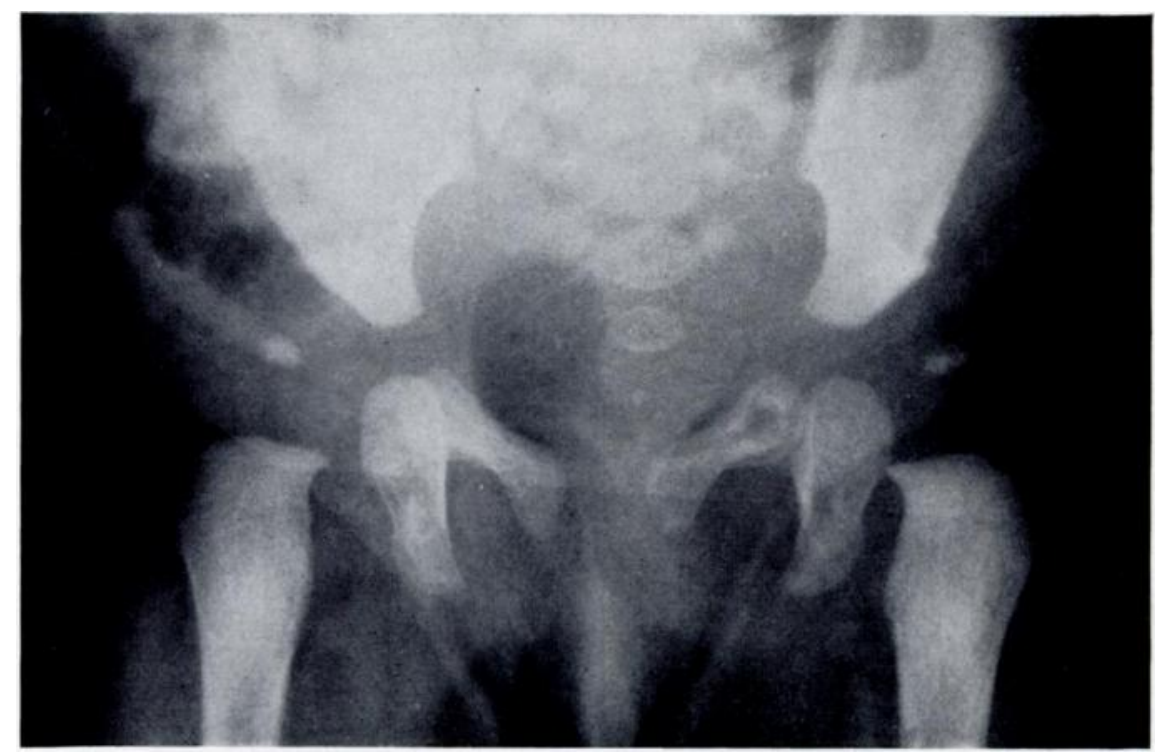

Fig. 1

A radiograph at four weeks suggesting partial displacement of the right hip in an infant with a family history of dislocation but with a negative "clunk" sign at birth.

at birth was negative. A sister, however, had had a complete dislocation, and in view of the minor displacement shown in the radiograph, the infant's hips were splinted with a satisfactory result.

Minor degrees of displacement warrant treatment because young adults with no previous history of hip trouble not infrequently present with painful arthrosis due to acetabular dysplasia.

In the seven-year period reviewed (Table I), out of 31,961 births there were 100 cases of luxation with a positive "clunk" sign at the time of re-examination, giving an incidence of approximately three per 1,000 births. (The incidence of frank dislocation in young children in Great Britain used to be estimated at approximately three per 2,000 births.) There were 126 unstable hips, and 123 suspect hips were considered normal. As previously mentioned, four dislocations escaped detection by routine examination soon after birth.

\section{COMPLICATIONS OF TREATMENT}

Ninety-two out of 100 luxated hip joints became anatomically normal with the aid of routine splintage. Two showed some deformity of the femoral head, five had to be reduced surgically and one required derotation osteotomy (Table I). In the unstable group there were no complications. The four missed dislocations were successfully reduced by operation at a later age.

VOL. 54 B, NO. 1, FEBRUARY 1972 
Seven out of the eight complications occurred in the first four-year period 1962 to 1965 , with no less than five in 1965 . In the next three years 1966 to 1968 there has so far been only one complication, a failure of initial reduction in 1968.

The complications of early treatment are: 1) failure of initial reduction, due either to inadequate splintage or to intra-articular obstruction; 2) failure to maintain reduction, again due either to inadequate splintage or to intra-articular obstruction; 3 ) deformity of the upper femoral epiphysis or metaphysis; or 4) persistent anteversion of the femoral neck.

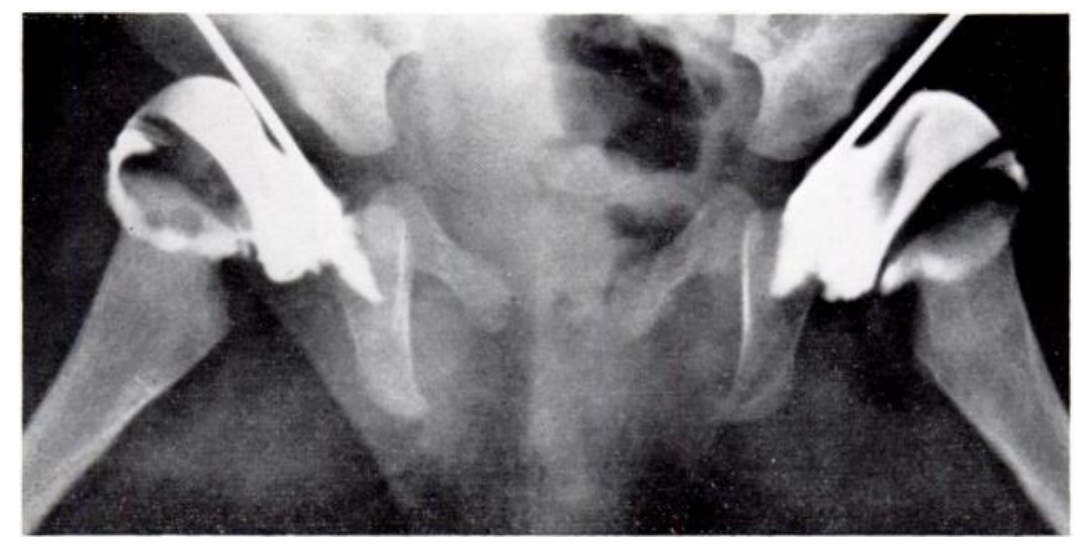

Fig. 2
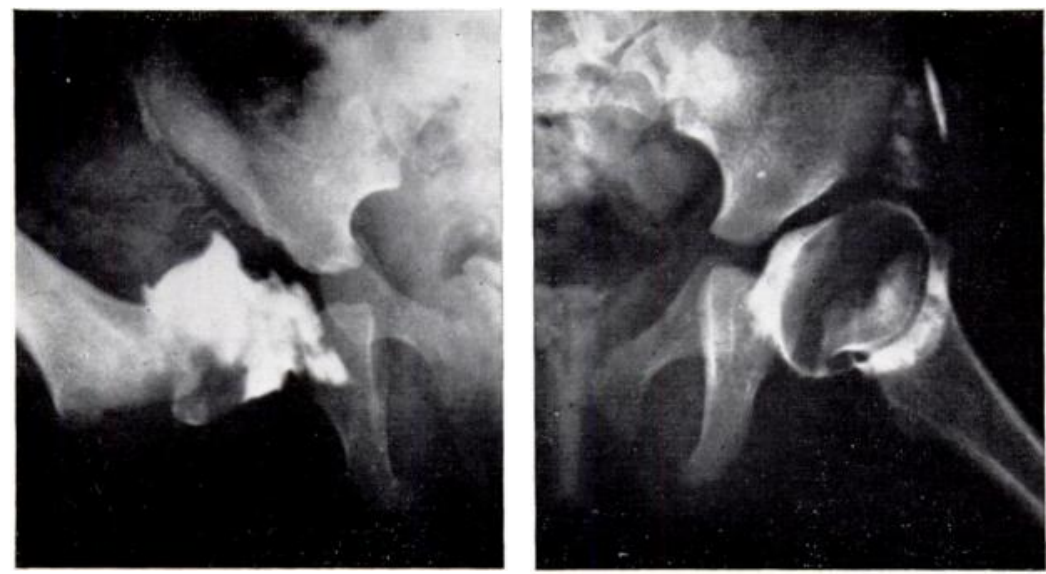

Fig. 3

Figure 2-Arthrograph showing obstruction in both hips which could not be reduced at birth. Figure 3-Arthrograph one year later showing an inverted limbus on the left and a fold of capsule with an inverted limbus on the right side.

Failure of initial reduction--During the seven-year period under review there was one case in which the hips could not be held reduced in the Malmö splint. Arthrography showed on the left side inversion of the limbus and a fold of capsule (Fig. 2). Gentle traction was applied but abandoned after six weeks, when it was decided to leave the child until she was old enough for operation. At one year there was deformity of the metaphysis. Arthrography now showed only an inverted limbus on the left (Fig. 3), which meant that there was a closer fit but more damage to the metaphysis. On the right side there was more displacement, with an inverted fold of capsule but less deformity of the metaphysis. The hips were reduced on an abduction 
frame and treated by excision of the limbus (Fig. 4) and bilateral Salter's osteotomy, giving stable reductions and functionally normal joints. The radiograph six years later (Fig. 5) showed residual deformity of the femoral heads, which was considered to be due to the initial attempt at reduction in the presence of an obstructing limbus.

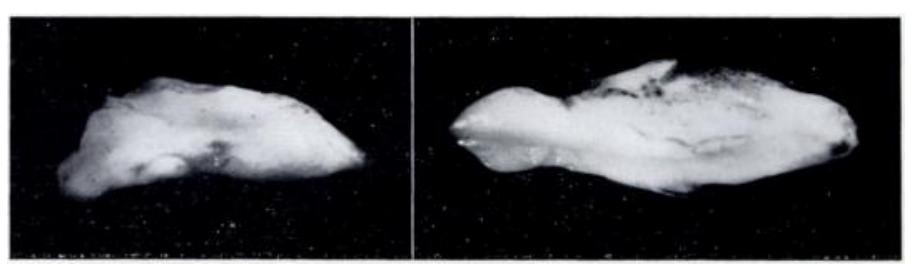

FIG. 4

Specimens of inverted limbus excised from both hips (life size).

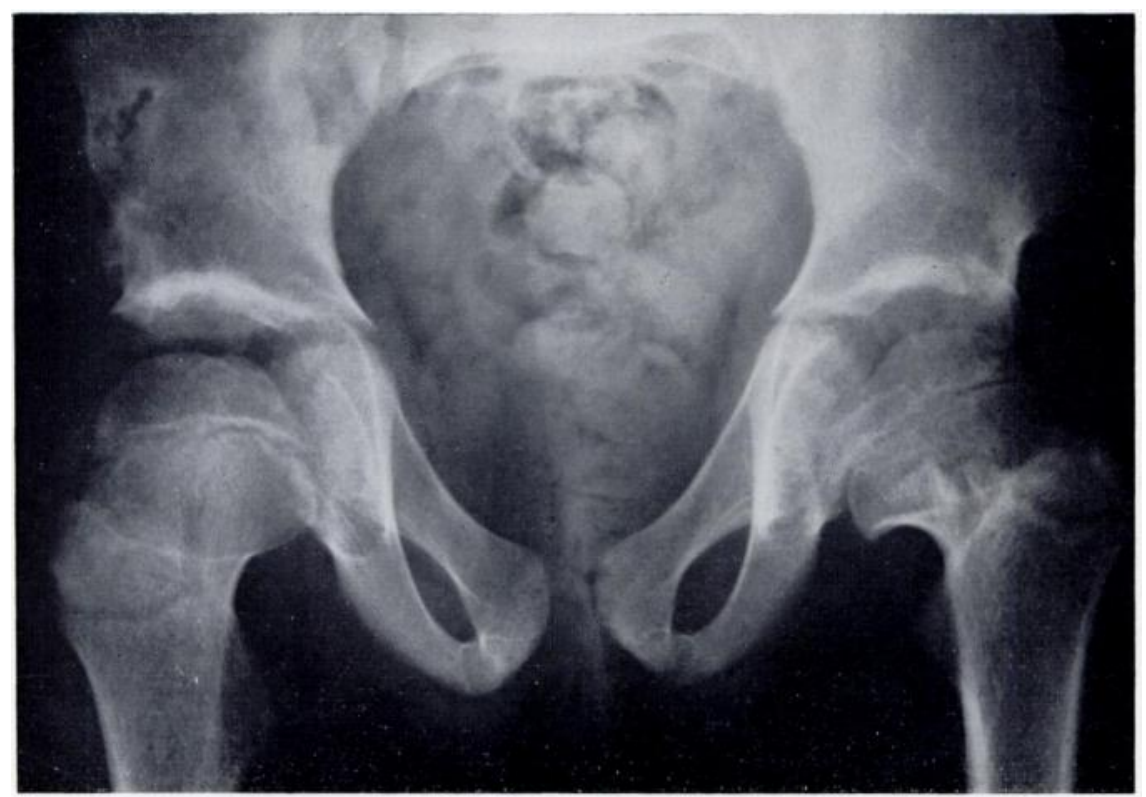

Fig. 5

Radiograph of same patient as shown in Figures 2 and 3 six years later. The femoral head on the right is enlarged and the femoral head and neck on the left are deformed.

Failure to maintain reduction-In this group reduction appears to be satisfactory as judged by radiographs in the Malmö splint, but displacement occurs on mobilisation. In the case shown in Figure 6 the initial reduction appeared satisfactory but the left hip subsequently became displaced, with early deformity of the metaphysis (Fig. 7). Arthrography showed an inverted limbus which was considered responsible for affecting the epiphysial growth cartilage. The limbus was excised at eight months and stable reduction was achieved, but with residual coxa vara which was subsequently improved by valgus osteotomy (Fig. 8).

Deformity of the epiphysis or metaphysis-In these difficult cases arthrography suggests that reduction by abduction in the presence of an inverted limbus may cause pressure changes, particularly in the early months of life. There seem to be two vulnerable areas-the ossific nucleus itself and the epiphysial growth cartilage. The nucleus has good powers of recovery but damage to the growth cartilage leads to deformity of the metaphysis.

VOL. 54 B, NO. 1, FEBRUARY 1972 


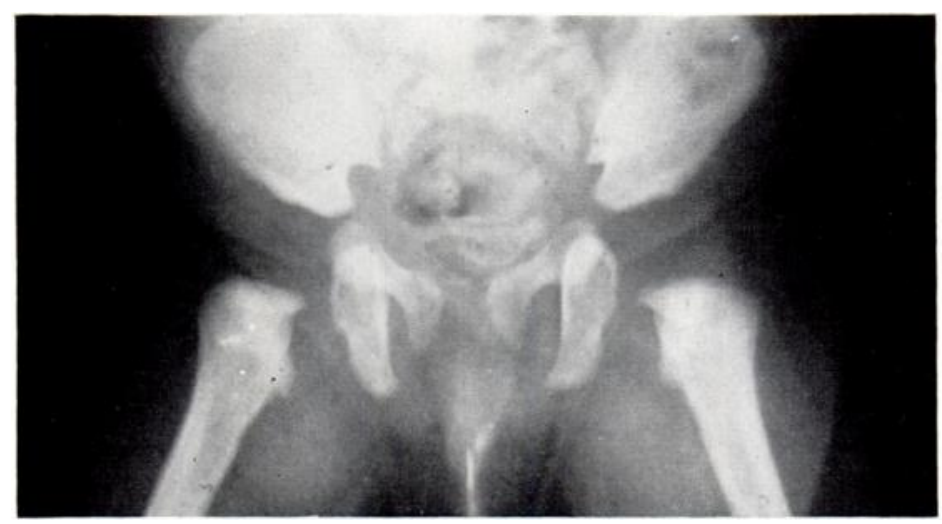

FIG. 6

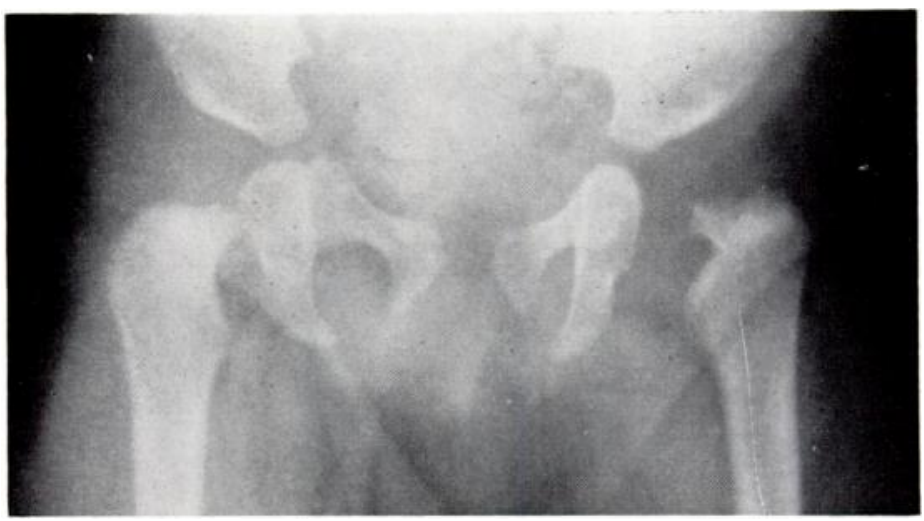

FIG. 7

Figure 6-These hips appeared reduced when the Malmö splint was removed. Figure 7-Five months later the left hip was displacing and deformity of the femoral neck was apparent. An inverted limbus was demonstrated by arthrography.
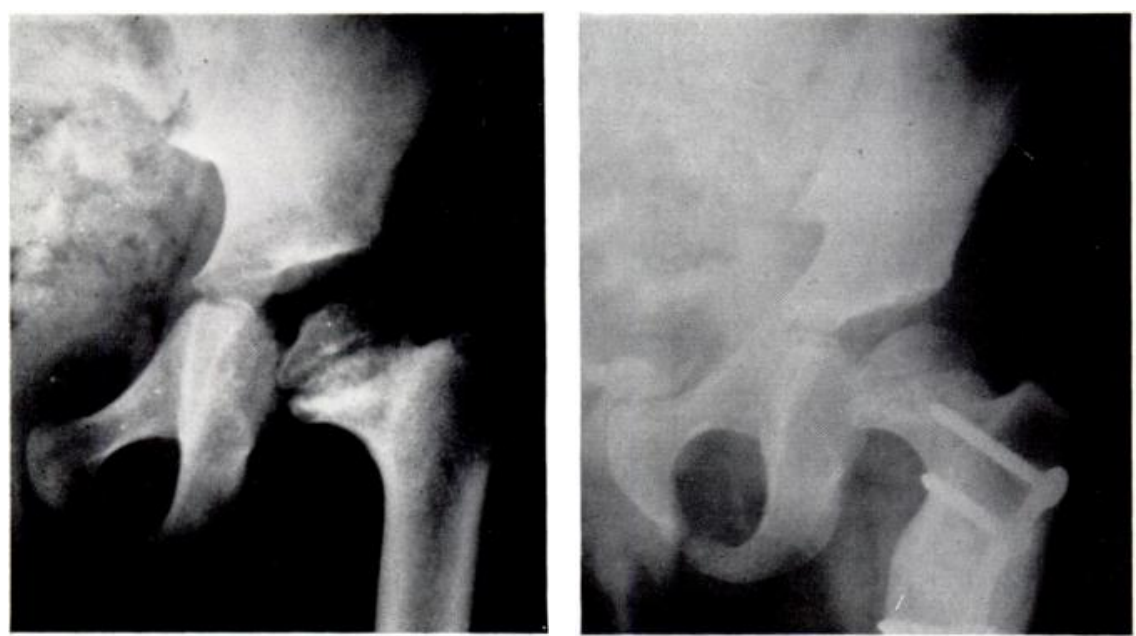

FIG. 8

The left hip was reduced after excision of the limbus but there was deformity of the metaphysis with coxa vara. The coxa vara was corrected by osteotomy. 
Figure 9 shows irregular ossification in a hip that had been held reduced on a Malmö splint but later displaced slightly. The joint improved, however, after weight-bearing was begun and the epiphysis developed normally, giving a satisfactory result four years later.

Figure 10 shows a hip in which displacement persisted despite routine splintage, due to an inverted limbus demonstrated by arthrography. There was already some deformity of the
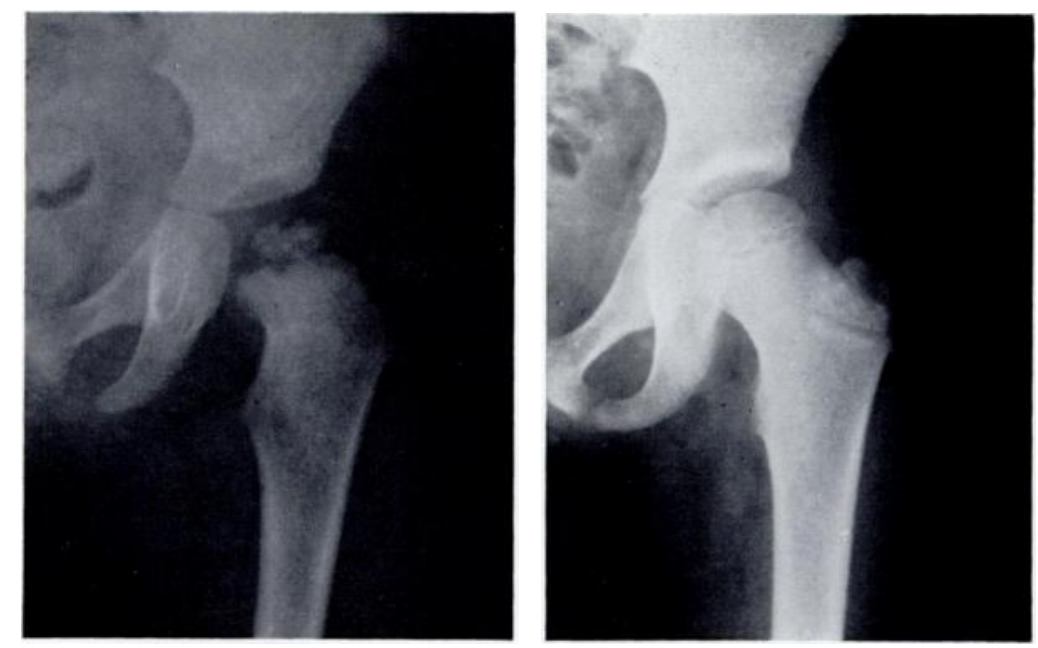

Fig. 9

Osteochondritis of the left hip following apparently successful reduction on a Malmö splint, but normal appearances four years later.
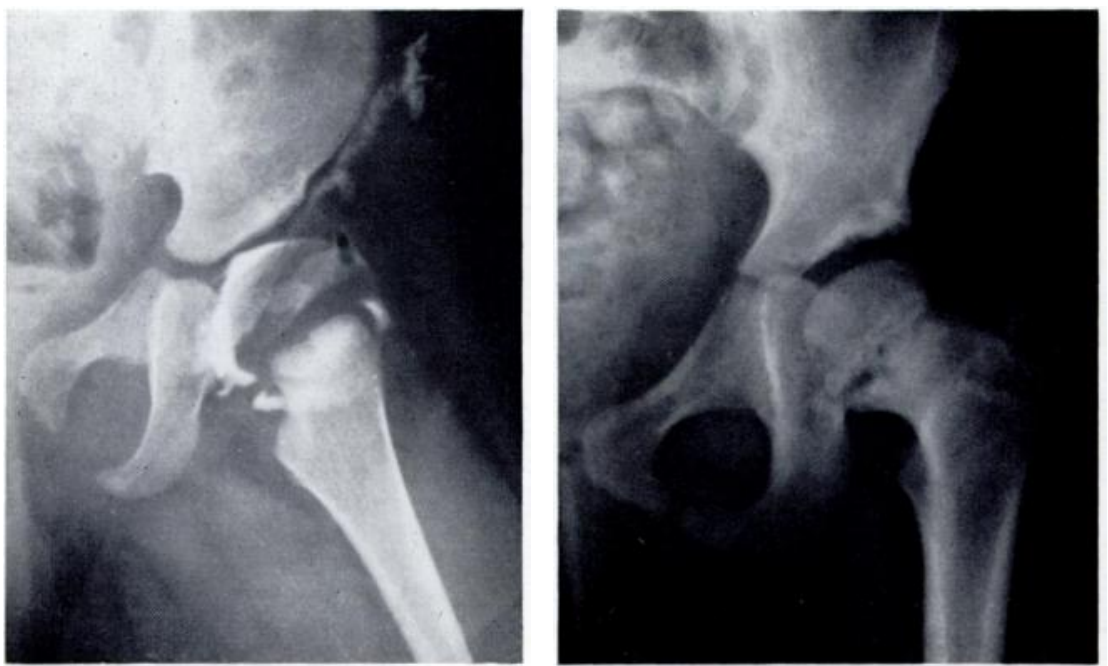

Fig. 10

A hip that displaced slightly following reduction on a Malmö splint. The arthrograph demonstrates inversion of the limbus. Note early deformity of the metaphysis. Successful reduction followed excision of the limbus. Note the residual coxa vara three years later.

metaphysis. The limbus was excised at eight months and good reduction was obtained. There was residual deformity of the metaphysis with coxa vara three years later.

Persistent anteversion-In some cases anteversion corrects slowly, a process which seems to depend to some extent on the activity of the child. Prolonged splintage should never be used to correct anteversion, which almost always will eventually respond to weight-bearing.

VOL. 54 B, NO. 1, FEBRUARY 1972 


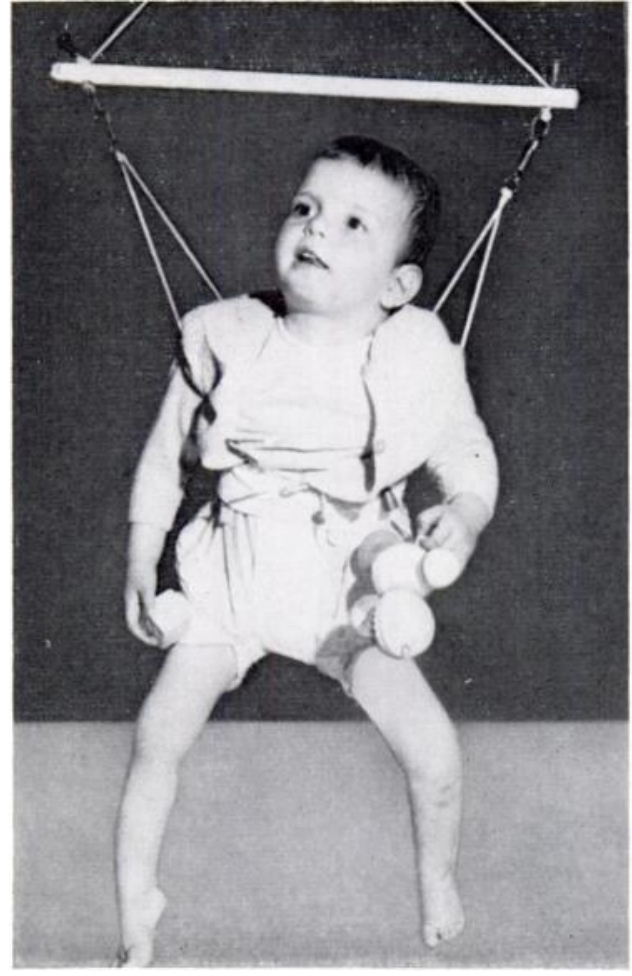

Fig. 11

To show the "baby-bouncer" apparatus.

Weight-bearing with assistance is encouraged when the abduction splint is removed, and it may be supplemented by using the "baby-bouncer" apparatus (Fig. 11).

If there is no intra-articular obstruction the anteversion may be allowed to correct itself during the first three years of life. Infants with marked anteversion often walk with an in-toeing gait, so that the weight-bearing position of the joints is much more satisfactory than might appear from the supine radiograph.

In this series of 100 luxated hips increased anteversion had corrected itself by the age of three years except in one case, in which bilateral derotation osteotomy was carried out at the age of four.

\section{TREATMENT OF HIP DISPLACEMENT IN THE EARLY MONTHS OF LIFE}

The recent emphasis on early detection has meant that a number of children from a wide area have been referred either with displacement after routine splintage or with the diagnosis made before the time of walking. These patients pose special problems because of their small size and because of the vulnerability of the upper femoral epiphysis and metaphysis to pressure from an inverted limbus during prolonged splintage.

Figure 12 shows the arthrograph of an infant of five months referred because the left hip was found displaced after routine splintage. An inverted limbus was demonstrated on the left side, whereas the right side was normal. Conservative reduction was followed by good development of the acetabulum, but at the age of one year there was deformity of the epiphysis and metaphysis. Three years later the hip was still fully reduced and the epiphysis had developed well, but there was deformity of the lateral part of the growth plate and metaphysis (Fig. 13).

A normal hip has always been obtained by conservative treatment in cases of displacement when the arthrograph demonstrated no intra-articular obstruction.

The problems in these young infants are the possible presence of an inverted limbus and the persistence of increased anteversion. Excision of the limbus should be a relatively minor procedure. Correction of anteversion by derotation osteotomy, however, necessitates the insertion of metal and a second operation to remove it.

An attempt has been made to avoid these pressure changes by combining excision of the limbus with frog position plasters to correct anteversion. It is true that the frog position can lead to osteochondritic changes in the epiphysis, but this occurs only when the hips are abducted in the presence of an inverted limbus or when they are held in extreme abduction. In a trial series, deformity of the upper femur did not occur after excision of the inverted limbus unless there had been a previous period of splintage in wide abduction.

Figure 14 shows the arthrograph of a left hip which appeared to have been well reduced on a Malmö splint at three months but which displaced on mobilisation. An inverted limbus was demonstrated and excised at one year (Fig. 15). The hips were then immobilised in internal rotation in a spica for one month, followed by the frog position for four months. Three years later the hip was radiographically normal (Fig. 16). 


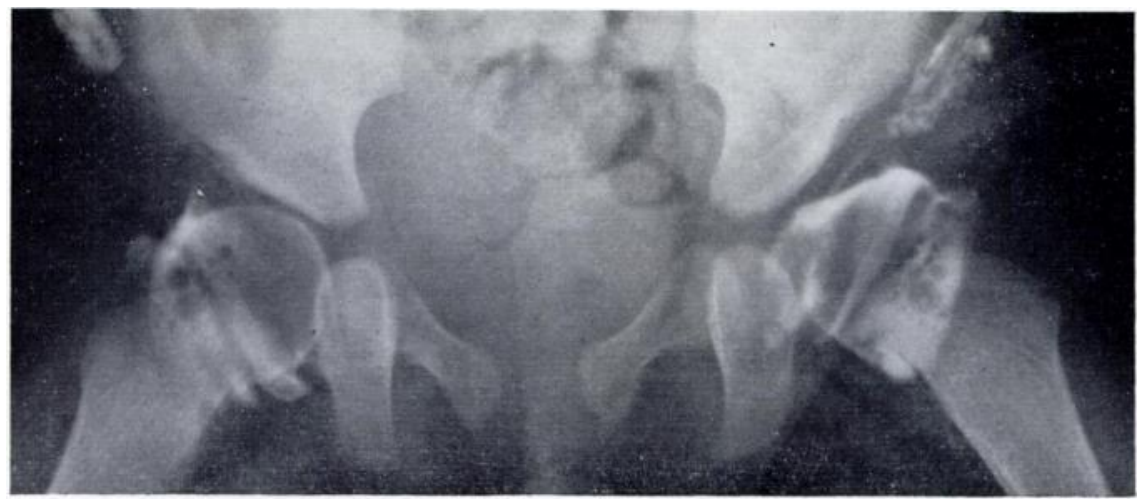

Fig. 12

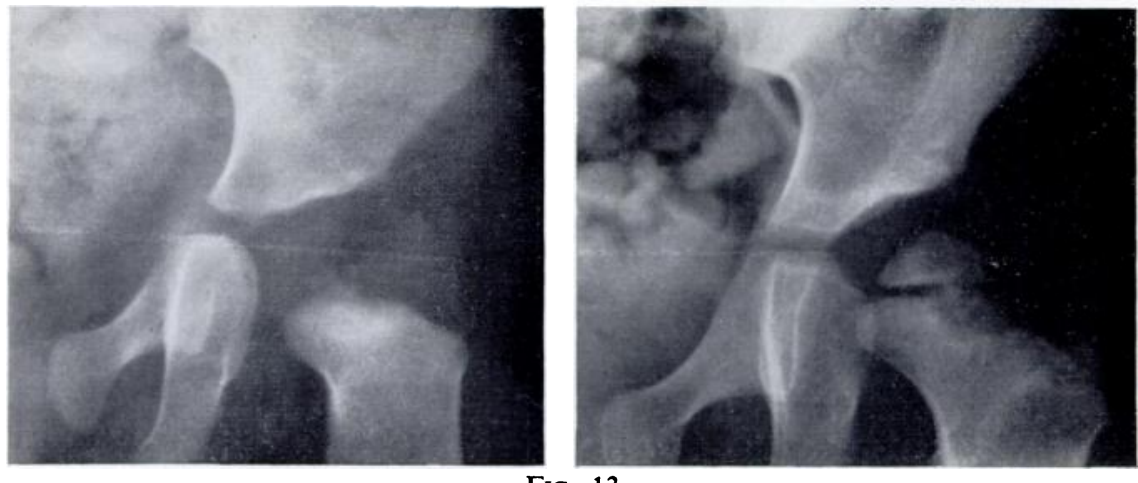

FIG. 13

Figure 12-Arthrograph of an infant aged 5 months with displacement of the left hip following routine splintage. The arthrograph of the right hip shows the normal "thorn" appearance, no deformity of outline and no pooling of radiopaque fluid. The arthrograph of the left hip shows no "thorn" and some pooling. Figure 13-The left hip was reduced by conservative reduction but showed deformity of the femoral epiphysis and metaphysis at 1 year. Three years later the hip remained reduced, with recovery of the epiphysis but irregularity of the growth plate and metaphysis laterally.

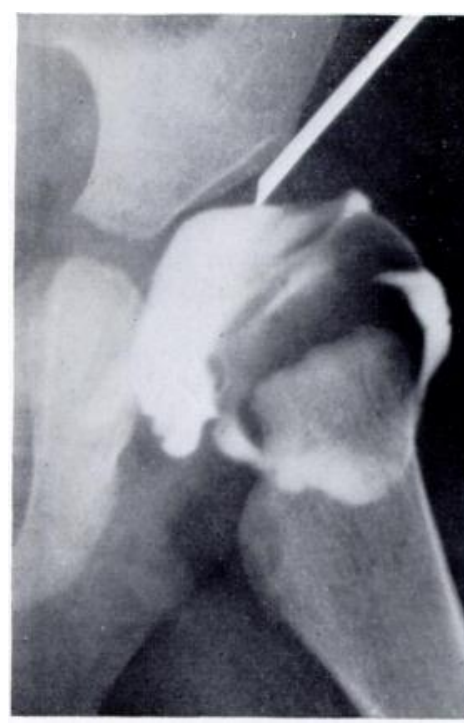

Fig. 14

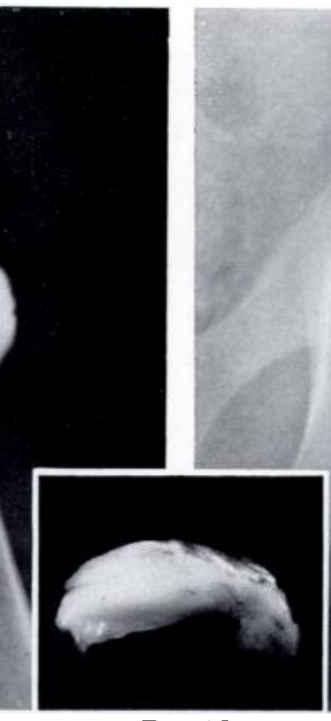

FIG. 15

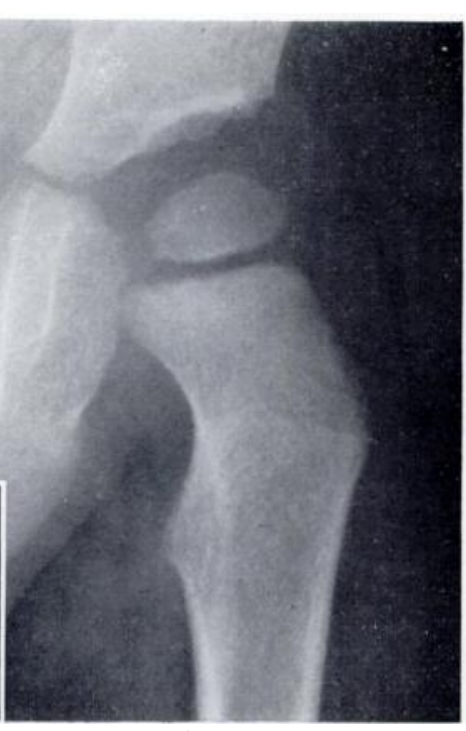

Fig. 16

Figure 14-Arthrograph of a left hip which displaced following apparent reduction on a Malmö splint. An inverted limbus is demonstrated lying just lateral to the needle point and causing a filling defect. Figure 15-Specimen of limbus removed at one year (life size). Figure 16-The hip three years later: normal appearance.

VOL. 54 B, NO. 1, FEBRUARY 1972 
In this trial series eighteen infants under one year of age had excision of the limbus followed by a plaster spica in the frog position for four months to correct anteversion. In four of the eighteen cases the anteversion did not correct and derotation was carried out. A longer period in the frog position might have been more effective.

This method of treatment in the early months is therefore not completely reliable, but the results demonstrate that a frog position plaster correctly applied does not produce pressure changes in the upper end of the femur in the absence of intra-articular obstruction.

\section{SUMMARY}

1. Some problems in the early diagnosis and management of congenital dislocation are discussed.

2. In a well-staffed maternity unit one dislocation completely escaped early detection in every 8,000 births over the period 1962 to 1968 inclusive.

3. The complications of early treatment on a Malmö splint are initial failure to obtain reduction, failure to maintain reduction, deformity of the upper femoral epiphysis or metaphysis, and persistent anteversion of the femoral neck.

4. Arthrography suggests that failure of early splintage and deformity of the upper femur are due to attempted reduction in the presence of an inverted limbus.

5. A trial method of treatment of frank displacement in the first year of life has been carried out by combining excision of the inverted limbus with a period in a frog position plaster to correct anteversion. This method avoided changes in the upper femur but failed to correct anteversion in four out of eighteen cases.

I gratefully acknowledge the cooperation of the obstetricians of the Simpson Maternity Pavilion and I am indebted to the paediatric staff who have carried out the initial examinations.

\section{REFERENCE}

Rosen, S. von (1962): Diagnosis and Treatment of Congenital Dislocation of the Hip Joint in the Newborn. Journal of Bone and Joint Surgery, 44-B, 284. 